\title{
Microenvironment in the pathogenesis of gastric cancer metastasis
}

\author{
Hiroshi Sawayama, Takatsugu Ishimoto, Hideo Baba \\ Department of Gastroenterological Surgery, Graduate School of Medical Sciences, Kumamoto University, Kumamoto 860-8556, \\ Japan.
}

Correspondence to: Prof. Hideo Baba, Department of Gastroenterological Surgery, Graduate School of Medical Sciences, Kumamoto University, 1-1-1 Honjo, Kumamoto 860-8556, Japan. E-mail: hdobaba@kumamoto-u.ac.jp

How to cite this article: Sawayama H, Ishimoto T, Baba H. Microenvironment in the pathogenesis of gastric cancer metastasis. $J$ Cancer Metastasis Treat2018;4:10. http://dx.doi.org/10.20517/2394-4722.2017.79

Received: 21 Nov 2017 First Decision: 25 Dec 2017 Revised: 18 Jan 2018 Accepted: 3 Feb 2018 Published: 28 Feb 2018

Science Editor: Masayuki Watanabe Copy Editor: Jun-Yao Li Production Editor: Huan-Liang Wu

\begin{abstract}
Tumor tissues contain cancer cells, other cellular and non-cellular components. Tumor microenvironments consist of cancer cells and various types of stromal cells, cancer associated fibroblasts, bone marrow-derived cells, endothelial cells, and hematopoietic cells, mainly tumor-associated macrophages and tumor-infiltrating lymphocytes. Increasing recent evidence has demonstrated that alteration of tumor microenvironments is deeply implicated in tumor progression and metastasis in gastric cancer (GC) patients. Recent investigations have provided insights into the molecular mechanisms of the interaction between tumor cells and tumor microenvironments. Interactions between cancer cells and their microenvironment with cytokines and microRNA in extracellular vesicles, such as the exosome, can have a substantial impact on tumor characteristics. Alterations in the tumor microenvironment may play a crucial role in facilitating the progression of tumor cells and metastasis, as well as the activation of cell signaling pathways, which are associated with GC cell proliferation and invasion by genetic or epigenetic alterations. In this review, significant molecular insights into the tumor microenvironment, which consist of cancer associated fibroblasts, bone marrow-derived cells, tumor-associated macrophages and tumor-infiltrating lymphocytes; the interactions between cancer cells and their microenvironment; and the clinical impacts of alterations of GC microenvironments will be discussed.
\end{abstract}

Keywords: Tumor microenvironments, cancer associated fibroblasts, bone marrow-derived cells, tumor-associated macrophages, tumor-infiltrating lymphocytes

\section{INTRODUCTION}

Gastric cancer (GC) is the fourth most commonly diagnosed cancer worldwide ${ }^{[1]}$. Surgical resection with lymph node dissection is the most effective treatment for resectable GC; the standard surgical procedure for

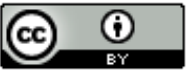

(C) The Author(s) 2018. Open Access This article is licensed under a Creative Commons Attribution 4.0 International License (https://creativecommons.org/licenses/by/4.0/), which permits unrestricted use, sharing, adaptation, distribution and reproduction in any medium or format, for any purpose, even commercially, as long as you give appropriate credit to the original author(s) and the source, provide a link to the Creative Commons license, and indicate if changes were made.

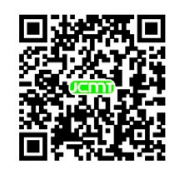


GC is reportedly gastrectomy with D2 dissection ${ }^{[2-4]}$. However, distant metastasis or disseminated relapses are experienced even after curative resection. Multidisciplinary treatment, perioperative chemotherapy and radiotherapy are other treatment options, and immunonutritional support is effective supportive care for GC. Prognosis of GC patients has been improved by multidisciplinary treatment. However, some patients experience recurrence after curative resection with perioperative therapy. Patients with unresectable GC also suffer from tumor progression and metastasis, even if they are treated with stronger therapeutic agents.

Trastuzumab and ramucirumab [targeting human epidermal growth factor receptor 2 (HER2) and vascular endothelial growth factor receptor 2, respectively] have been approved for treating $\mathrm{GC}^{[5-7]}$ and these molecular targeting agents improve GC patients' survival; however, many molecular targeting drugs that have entered clinical trials for GC failed. Therefore, more effective treatment, which targets other mechanisms, should be sought for these patients. The efficacy and safety of nivolumab, a human immunoglobulin G-4 monoclonal antibody inhibitor of programmed death-1, were confirmed in GC patients ${ }^{[8]}$. Recent studies have revealed that programmed death-ligand-1 (PD-L1) expression is associated with the microenvironments in GC. The Cancer Genome Atlas project demonstrates that GC cases can be divided into four subtypes: tumors positive for Epstein-Barr virus (EBV), tumors with microsatellite instability (MSI), genomically stable (GS) tumors and tumors with chromosomal instability (CIN). EBV positive tumors are associated with phosphatidylinositol 4,5-bisphosphate 3-kinase catalytic subunit alpha mutations, extreme DNA hypermethylation, and amplification of Janus kinase 2 (JAK2), PD-L1 and PD-L2. Tumors with MSI exhibit elevated mutation rates. GS tumors are enriched for the diffuse histological variant and mutations of Ras homolog gene family member A (RHOA) or fusions involving RHO-family GTPase-activating proteins. Tumors with CIN show marked aneuploidy and focal amplification of receptor tyrosine kinases ${ }^{[9]}$. Identification of these subtypes can prove to be valuable for developing strategies for targeted therapies for cancer.

Increasing recent evidence has shown that tumor microenvironments of GC, as well as gene expression pattern, are deeply implicated in tumor progression and metastasis. Tumor microenvironments consist of cancer cells and various types of stromal cells, bone marrow-derived cells (BMDCs), mast cells (MCs), tumor-infiltrating lymphocytes (TILs), tumor-associated macrophages (TAMs) and cancer associated fibroblasts (CAFs). Interactions between cancer cells and their microenvironment with cytokines and microRNA (miRNA) in extracellular vesicles, such as the exosome, can have a substantial impact on tumor characteristics. Alterations in the tumor microenvironment may play a crucial role in facilitating the progression of tumor cells as well as the activation of cell signaling pathways by the genetic or epigenetic alteration of cancer cells.

In this review, important molecular insights into clinical impacts of the tumor microenvironment of GC will be discussed.

\section{BONE MARROW-DERIVED CELLS}

BMDCs which are recruited to tissue injury sites are thought to represent a potential source of malignancy. Chronic infection with Helicobacter felis induces the intensity of bone marrow-derived inflammation and repopulation of the stomach with BMDCs. Metaplasia and dysplasia to intra-epithelial cancer progress through the recruitment and accumulation of $\mathrm{BMDCs}^{[10]}$. Helicobacter pylori infection leads to development of chronic inflammation as well as the recruitment and accumulation of BMDCs in the gastric epithelial mucosa. Nearly $20 \%-25 \%$ of dysplastic lesions include cells that originate from the bone marrow ${ }^{[11,12]}$. Bone marrow cells may be associated with GC initiation and proliferation.

Recent studies have demonstrated the mechanism of BMDCs. Infection of gastrointestinal epithelial cells by Helicobacter pylori stimulates the migration of BMDCs. The nuclear factor-kappa B (NF-kB) signaling 
pathway may play a major role in the ability of infected epithelial cells to induce BMDC migration ${ }^{[13]}$. Bone marrow-derived myofibroblasts secrete high levels of murine IL- 6 and hepatocyte growth factor (HGF), which activate transforming growth factor- $\beta 1$ (TGF $\beta 1$ ) and signal transducers and activators of transcription (STAT3) in GC cells. Bone marrow-derived myofibroblasts that increase IL-6/HGF and cancer cell-derived TGF $\beta 1$ mediate the interactions between bone marrow-derived myofibroblasts and GC cells, which regulate promotion of tumorigenesis and cancer stemness ${ }^{[14]}$. NF-kB is regulated by miRNAs. miRNA155-5p downregulation induces BMDCs to acquire a GC mesenchymal stem cell (MSC)-like phenotype. The function depends on NF-kB p65 activation. This mechanism is the cancer associated MSC remodeling in the tumor microenvironment ${ }^{[15]}$. The association between BMDCs and chemokines has been analyzed to evaluate the chemotaxis-stimulating factor from diffuse-type GC cells using BMDCs in an in vitro assay. CXCL1 from GC cells stimulates the recruitment of BMDCs into tumor stroma via CXCR2 signaling of $\mathrm{BMDCs}^{[16]}$.

Some markers, including CD13, CD15, CD73, CD140b, CD144, CD146, CD164 and CD271, have been used to identify MSCs ${ }^{[17,18]}$. Neural crest nerve growth factor receptor (CD271) was reported as a marker of bone marrow-derived stromal cells ${ }^{[18,19]}$. The role of bone marrow-derived stromal cells expressing CD271 has been evaluated in GC patients. CD271 expression in stromal cells is significantly associated with macroscopic type- 4 cancers, diffuse type tumors and depth of invasion. In one study, patients $(n=279)$ with CD271positive stromal cells had a worse prognosis than patients with CD271-negative stromal cells ${ }^{[20]}$.

Some studies have demonstrated that the interaction between BMDCs and GC cells is an important factor in cancer development and progression and may be associated with the survival of GC patients.

\section{MAST CELLS}

MCs play an important role in immunity and defend the body against viruses and bacteria. MCs are also known for causing uncomfortable symptoms due to their release of histamine and other mediators which cause allergic responses. MCs constitute a long-lived, heterogeneous cellular population originating from the bone marrow ${ }^{[21]}$. Mast cell density (MCD) in GC was found to be higher than that in the control. Moreover, MCD in well-differentiated adenocarcinoma was higher than that in poorly-differentiated adenocarcinoma ${ }^{[22]}$. MCs were recognized by their modulatory activities in inflammation and angiogenesis. Tryptase was used as a marker for MCs. The expression of tryptase and Foxp3 were positively correlated. Infiltration of MCs was found to be significantly associated with an advanced stage of $\mathrm{GC}^{[23]}$. MCs density increased with an increase in malignancy grade and was highly correlated with the extent of angiogenesis ${ }^{[24]}$. However, increased tryptase expression was associated with better survival outcome in early-stage GC patients after surgical resection. These opposing effects may indicate the possibility of two mast cell phenotypes $(\mathrm{MC} 1 \text { and } \mathrm{MC} 2)^{[25]}$. MCs were associated with angiogenesis and tumor progression in diverse tumors $^{[21]}$, however contradictory results were also reported in other cancers ${ }^{[25,26]}$. The relation between MCs and GC remains largely unknown and further investigations regarding MCs, including other factors, are needed.

\section{TUMOR-INFILTRATING LYMPHOCYTES}

TILs consist of T cells, B cells, and NK cells. The subset of T cells is represented by CD8+ cytotoxic T cells, CD4+ T helper cells, CD45RO+ memory T cells, FOXP3+ regulatory T cells and NK cells. These cells can infiltrate stroma and tumor cells, and are considered a manifestation of the host immune response against tumor cells ${ }^{[27]}$.

Thirty-one studies (incorporating 4,185 patients) were conducted to evaluate the relationship between TILs and GC prognosis. The amount of $\mathrm{CD} 8+, \mathrm{FOXP}_{3}+\mathrm{CD} 3+, \mathrm{CD} 57+, \mathrm{CD} 20+, \mathrm{CD} 45 \mathrm{RO}+$, Granzyme $\mathrm{B}+$ and 
T-bet+ lymphocytes is a significant advantage to survival; moreover, the amount of CD3+ TILs in the intratumoral compartment is the most significant prognostic marker [pooled hazard ratio $(\mathrm{HR})=0.52 ; 95 \%$ confidence interval $(\mathrm{CI})=0.43-0.63 ; P<0.001]$. CD4+ TILs are not statistically associated with prognosis. FOXP $3+$ TILs show bidirectional prognostic roles, which have a positive effect in the intra-tumoral compartment (pooled $\mathrm{HR}=1.57 ; 95 \% \mathrm{CI}=1.04-2.37 ; P=0.033$ ) and a negative effect in the extra-tumoral compartment $(\text { pooled HR }=0.76 ; 95 \% \mathrm{CI}=0.60-0.96 ; P=0.022)^{[28]}$.

Stromal TIL-positivity was significantly associated with GC patient survival in multivariate analysis. High densities of intratumoral-TIL has a tendency to be a favorable outcome indicator for GC patient survival ${ }^{[2]}$. The prognostic impact of TILs has also been evaluated for GC patients with microsatellite instability-high (MSI-H). Higher densities of both intratumoral CD8+ and FOXP3+ TILs are significantly associated with longer survival ${ }^{[30]}$. The prognostic impact of TILs has also been evaluated for patients with EBV-associated GC. EBV-associated GCs are more prevalent in $\mathrm{CD} 8+$ and FOXP3 + cell infiltration than EBV-negative GCs. CD8 expression and Foxp3 expression cell infiltration are associated with longer overall survival, whereas PD-L1 expression correlates with shorter overall survival ${ }^{[31]}$.

Most recent studies have focused on the significant association between PD-L1 expression and TILs. PD-L1 expression is associated with high densities of TILs, mismatch repair deficiency and EBV positivity, but is not a prognostic factor ${ }^{[32]}$. PD-L1 expression alone on tumor cells is not associated with survival of GC patients; however, patients with positive PD-L1 expression on a high density of TILs have a significantly shorter 5-year overall survival than those with negative PD-L1 expression. PD-L1 expression on TILs is an independent prognostic factor ${ }^{[33]}$. It is associated with the corresponding immunoscore, which is quantified by the number of high-density areas of $\mathrm{CD} 3+$ and $\mathrm{CD} 8+$ TILs, both in the tumor regions and compartments of MSI-H advanced GC ${ }^{[34]}$. The levels of immunosuppressive protein expression PD-L1, cytotoxic T-lymphocyte antigen 4 (CTLA-4), and indoleamine 2,3-dioxygenase (IDO) in tumors and the densities of immune cells $[\mathrm{CD} 3(+), \mathrm{CD} 4(+), \mathrm{CD} 8(+)$, or $\mathrm{PD}-1(+)$ cells] within the tumor microenvironment have been evaluated by immunohistochemical analysis. $\mathrm{PD}-\mathrm{L} 1$ positive expression and a high-CD3 tumor microenvironment are favorable prognostic markers in $\mathrm{GC}^{[35]}$. Another study has also demonstrated that PD-L1 expression alone is not associated with overall survival; however, PD-L1-/CD8 high type is an independent indicator for longer overall survival compared with PD-L1+/CD8 high. Adaptation of a recent molecular classification ${ }^{[9]}$ based on EBV, MSI, E-cadherin and p53 showed no significant survival differences in this study. EBV+ and MSI-H GCs are associated with $\mathrm{PD}-\mathrm{L} 1+/ \mathrm{CD} 8$ high, and the PD-L1/CD8 status is associated with their prognostic significance in stage II/III GCs ${ }^{[36]}$. Recent studies have revealed that PD-L1 expression was significantly associated with GC patient prognosis only under the interaction between PD-L1 and TILs.

\section{TUMOR-ASSOCIATED MACROPHAGES}

TAMs play crucial roles in microenvironments. The polarization of macrophages into tumor-suppressive M1 or tumor-promoting M2 types is established in the microenvironment of $\mathrm{GC}^{[37]}$. TAMs represent up to 50\% of the tumor and are mainly M2 macrophages in invasive cancers. M2 macrophages support proliferation, invasion and metastasis by upregulating diverse growth factors, cytokines and extracellular matrix (ECM)-remodeling molecules, such as CCL2, CXCL12, CXCR4, TGF $\beta$, VEGF, PDGF, COX-2 and matrix metalloproteinases (MMPs) ${ }^{[38]}$. TAMs interact with T cells during tumor progression. M1 macrophages direct $\mathrm{T}$ cells towards Th1 tumoricidal responses. M1 macrophages are induced by NK cells that are produced by interferon- $\gamma($ IFN $-\gamma)$ to amplify anti-tumor activity ${ }^{[39,40]}$. TAMs are identified by immunohistochemistry with the anti-CD68 antibody (pan-macrophage). Especially, M2 macrophages are identified with the anti-CD163 antibody (M2 macrophage).

A meta-analysis of 12 studies ( $n=1388$ patients) was conducted to evaluate the relationship between TAMs and GC prognosis. High total TAM infiltration levels in GC patients are associated with worse overall 
survival $(\mathrm{HR}=1.70,95 \% \mathrm{CI}=1.39-2.09 ; P<0.001)$. A similar result was demonstrated for $\mathrm{M} 2$ macrophage infiltration $(\mathrm{HR}=1.71,95 \% \mathrm{CI}=1.19-2.45 ; P=0.004)$. In contrast, elevated M1 macrophage density in GC patients is associated with better overall survival $(\mathrm{HR}=0.46,95 \% \mathrm{CI}=0.33-0.65 ; P<0.001)$. This metaanalysis demonstrated that the numbers of infiltrating M2 macrophages and total TAMs may be negative prognostic factors for GC patients, while infiltrating M1 macrophages may be associated with a favorable survival rate ${ }^{[41]}$.

The mechanisms of GC progression affected by TAMs have been investigated. Macrophages induce the capillary formation of lymphatic endothelial cells. Co-culture with GC pretreated macrophages upregulate lymphangiogenic factors, including inflammatory cytokines, MMPs, adhesion molecules and vascular endothelial growth factor-C. Interaction between lymphatic endothelial cells and macrophages may be an important initial step in tumor lymphangiogenesis developing lymph node metastasis ${ }^{[22]}$. The high density of CD163+ TAMs (M2 macrophage) is an independent prognostic marker heralding prolonged disease-free survival. The prognostic implication of CD163+ TAMs might be determined by the proportional balance of TAMs and TILs in MSI-H GCs ${ }^{[43]}$.

Redox adaptation enables cancer cells to survive under increased oxygen species (ROS) stress. ROS produced by TAMs triggers CD44 expression through the suppression of miR-328 in GC cells ${ }^{[44]}$. Cluster of differentiation 44 (CD44) is a major adhesion molecule and a broadly distributed cell surface receptor for hyaluronic acid ${ }^{[45]}$. The CD44 gene is located on chromosome $11 \mathrm{p} 13$ and contains 20 exons, 10 of which are expressed in the standard form $(\mathrm{CD} 44 \mathrm{~s})^{[46]}$. CD44 isoforms, containing variant exon 6 (CD44v6), are identified by alternative splicing of at least 12 exons $^{[47]}$. CD 44 variant isoform $(\mathrm{CD} 44 \mathrm{v})$ is one of the cell surface markers of GC stem cells ${ }^{[48]}$. Furthermore, CD $44 \mathrm{v}$ contributes to defense against reactive ROS by stabilizing the glutamate-cystine transporter subunit $\mathrm{xCT}$, and promoting the synthesis of the primary intracellular antioxidant glutathione ${ }^{[49]}$.

Epithelial-mesenchymal transition (EMT), which is induced by TAMs, may play a key role in cancer metastasis. M2 macrophages secrete epidermal growth factor or TGFB, which stimulates $\mathrm{EMT}^{[50,51]}$. Epidermal growth factor activates the AKT pathway, which regulates $\beta$-catenin translocation. MMP7 and CD44, which are $\beta$-catenin downstream genes, are involved in macrophage-activated GC cell invasion ${ }^{[52]}$. E-cadherin and vimentin expression are markers of EMT. E-cadherin expression in GC cells co-cultured with TAMs is decreased, while vimentin expression in GC cells co-cultured with TAMs is increased ${ }^{[53]}$. Bmi1 is identified as a cancer stem cell marker, and M2 macrophages upregulate Bmi1 expression through miRNA$30 \mathrm{e}^{\star}$ suppression in $\mathrm{GC}^{[54]}$.

Recent studies have revealed the relationship between TAM infiltration and PD-L1 expression. TAM receptors (Tyro3, Axl and Mertk) upregulate the expression of PD-L1 in a breast cancer cell line. According to the data, M2 macrophages might activate PD-L1 expression in tumor cells. IFN- $\gamma$ is secreted by inflammatory cells and is associated with differentiation of macrophages. IFN- $\gamma$ was found to facilitate PD-L1 expression in tumor cells ${ }^{[5,56]}$. In GC, IFN- $\gamma$ might also influence the relationship between M2 macrophage infiltration and PD-L1 expression in tumor cells. TAM infiltration is also associated with the upregulation of PD-L1 expression in GC cells [Figure 1] ${ }^{[57]}$.

\section{CANCER ASSOCIATED FIBROBLASTS}

Tumor tissues contain cancer cells, other cellular and non-cellular components. The tumor stroma acts as an essential microenvironment of the cancer cells, which includes many types of non-cancerous cells and the ECM. Stromal fibroblasts are the major cellular constituents of the tumor stroma and are often called CAFs. CAFs contribute to the stiffening and remodeling of the stromal ECM, thereby offering an appropriate field for cancer cell invasion ${ }^{[58,59]}$. Cancer cells induce the conversion of these various types of cells into 


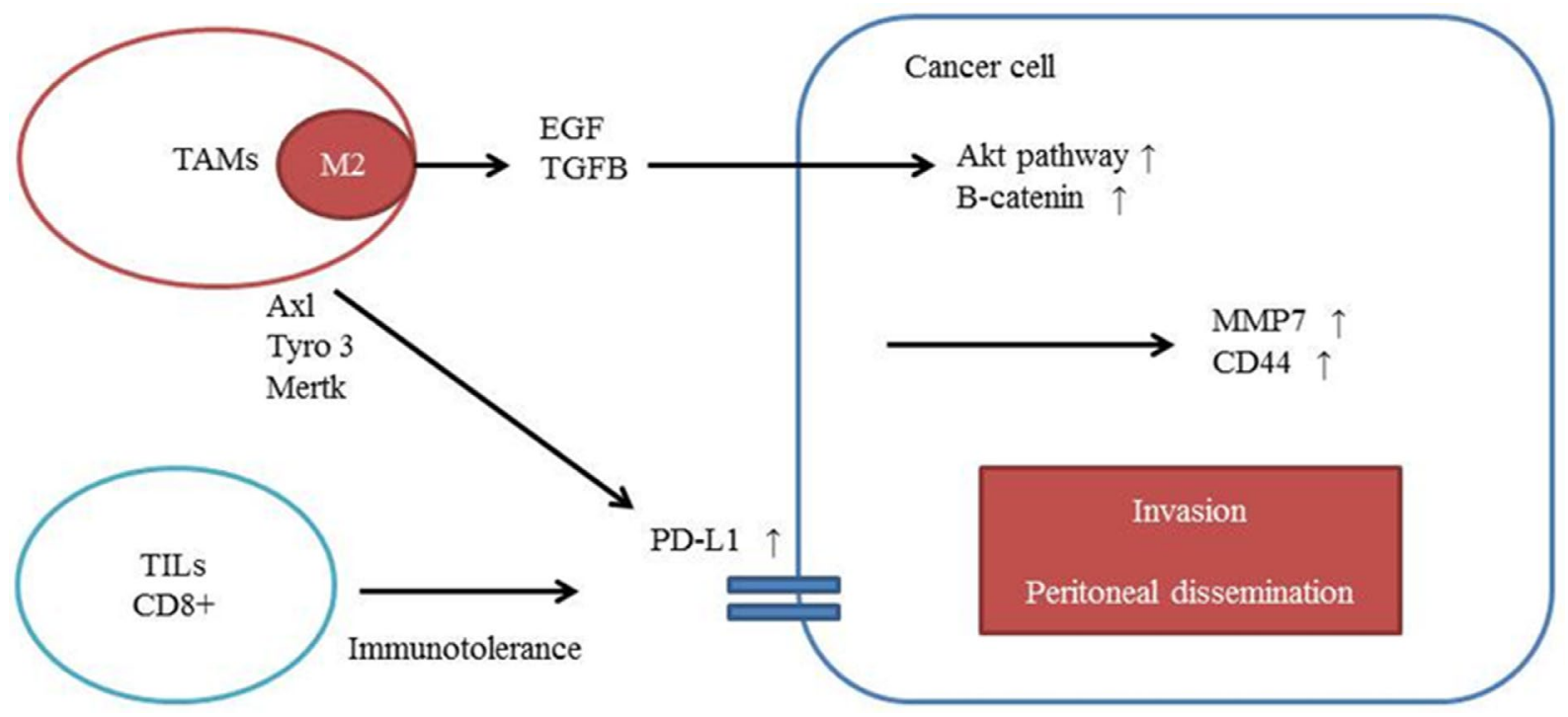

Figure 1. The mechanisms of GC progression affected by TAMs. M2 macrophages secrete EGF or TGFB. EGF activates the AKT pathway, which regulates $\beta$-catenin translocation. MMP7 and CD44 are involved in macrophage-activated GC cell invasion. TAM receptors (Tyro3, Axl and Mertk) upregulate the expression of PD-L1. GC: gastric cancer; TAM: tumor-associated macrophage; EGF: epidermal growth factor; TGFB: transforming growth factor- $\beta 1$; MMP: matrix metalloproteinase; PD-L1: programmed death-ligand-1; TIL: tumor-infiltrating lymphocyte

CAFs. CAFs acquire the properties of myofibroblasts, including expression of smooth muscle alpha$\operatorname{actin}^{[60]}$. Formation of myofibroblasts is associated with fibrosis and increases the risk of cancer. Many other studies have demonstrated that fibroblasts often have a position at center stage, orchestrating and actively participating in the transformation process. They are also spectators in the tumorigenic process ${ }^{[61]}$. Fibroblast activation protein- $\alpha$ (FAP) is a protein expressed in fibroblasts, such as CAFs, which are major components of the tumor microenvironment. FAP is potentially associated with GC patient survival ${ }^{[62]}$.

Recent investigations have demonstrated that interleukins, such as IL1A, IL1B, IL-6 and IL-17B, produced by CAFs, are associated with cancer progression and metastasis. In CAFs isolated from human diffuse-type GCs, inflammatory cytokines, such as IL1A, IL1B, and tumor necrosis factor (TNF), secreted by diffuse-type GC, induce rhomboid 5 homolog (RHBDF2) expression. RHBDF2 promotes cleavage of TGFB receptor 1 (TGFBR1) and motility of CAFs in response to TGFB1. These highly motile CAFs induce diffuse-type GCs to invade the ECM and lymphatic vessels. IL1A, IL1B and TNF status is associated with shorter overall survival of diffuse-type GC patients ${ }^{[63]}$. IL- 6 is also associated with CAFs; it has been produced by CAFs isolated from GC. The migration and EMT of GC cells are enhanced by CAFs through the secretion of IL-6, which activates JAK2/STAT3 pathway in GC cells. Inhibiting the JAK2/STAT3 pathway with a specific inhibitor markedly attenuates these phenotypes in GC cells induced by CAFs ${ }^{[64]}$. IL-17B increases the expression of stemness-related genes Nanog, Sox2 and Oct4 in MSCs, and the tumor promoting effect is enhanced. The condition medium from cultured MSCs after being treated with exogenous recombinant interleukin-17B (rIL-17B) promotes the proliferation and migration of GC cells. rIL-17B also activates the NF-kB, STAT3, $\beta$-catenin pathway in MSCs and the progression of GC is induced by IL-17B activating MSCs ${ }^{[65]}$.

miRNAs are a class of non-coding small RNA molecules, and expression of miRNAs in CAFs regulates an essential role in the communication between tumor cells and CAFs, as well as the expression of a number of target genes ${ }^{[66]}$. A miRNA microarray analysis from GC revealed the different expression of miRNA between CAFs and normal fibroblasts (NFs). In the study, four miRNAs were increased (miRNA-34b, 301a 106b and 93) and seven miRNAs were decreased (miRNA-483-3p, 26a, 7g, 148a, 145, 424 and 214) in CAFs compared with NFs. The expression of miRNA-106b is upregulated in CAFs established from patients with GC, and the expression level of miRNA-106b is associated with poor prognosis of GC patients. CAFs with downregulated miRNA-106b could significantly inhibit GC cell migration and invasion by targeting the phosphatase and 
tensin homolog ${ }^{[67]}$. In CAFs, miRNA-143 overexpression is derived from diffuse type GC compared with NFs. miRNA-143 promotes GC cell invasion by regulating the expression of collagen type III in CAFs, and miRNA-143 expression serves as a prognostic marker of $\mathrm{GC}^{[68]}$. The expression of miRNA-200b is downregulated by CAFs. miRNA-20ob downregulates zinc finger E-box-binding homeobox expression and upregulates E-cadherin expression in GC cells to repress tumor cell invasion and peritoneal dissemination ${ }^{[69]}$. Expression of miRNA-328 mediated by macrophages regulates CD44 signaling and may promote tumor progression by enhancing ROS defense ${ }^{[44]}$.

At least $20 \%$ of CAFs originate from the bone marrow and are derived from MSCs. Those MSC-derived CAFs were recruited to the tumor in a TGF- $\beta$ - and stromal-derived factor (SDF)- $1 \alpha$-dependent manner in mouse models of inflammation-induced gastric dysplasia (21316604). SDF-1 $\alpha$ produced by myofibroblasts promotes gastric epithelial proliferation, partly through CXCR4-positive gastric tissue stem progenitor cells, and plays a key role in gastric carcinogenesis ${ }^{[11]}$. CXCL12 is also associated with CAF-induced cancer progression. CXCL12 and Twist1 expression are correlated in CAFs present in gastric tumor specimens. Ectopic expression of Twist 1 in NFs suppresses premature senescence, whereas Twist 1 attenuation accelerates senescence in $\mathrm{CAFs}^{[70,71]}$.

Interleukins and miRNAs produced by CAFs are associated with cancer progression and metastasis of GC cells. Interactions between cancer cells and CAFs with interleukins or miRNAs can have a substantial impact on tumor characteristics and alteration of signaling pathways associated with proliferation and invasion of GC cells.

\section{CHEMOKINES}

Fibroblasts are a major component of the tumor stroma, and activated fibroblasts regulate solid tumor progression. The interaction between cancer cells and CAFs by chemokines has been suggested to be important for the progression of GC. Chemokines, more than 40 of which have been identified, are 8-10-kDa secreted proteins with $20 \%-70 \%$ homology in structure. They share the common functional activity as being chemotactic for leucocytes. Pro-inflammatory stimuli, such as IL-1, TNF- $\alpha$, lipopolysaccharide or pathogens produce inflammatory chemokines, which determine the migration of inflammatory cells. Chemokines bind to G protein-coupled receptors on leukocytes and stem cells, and they function through guanine nucleotide-binding proteins to control intracellular signaling that promotes the migration ability toward the chemokine source ${ }^{[72]}$.

CXCR4 and CXCR7 are important chemokine receptors that share the same ligand CXCL12. The association of CXCR4 and CXCL12 with GC patient prognosis was evaluated in a meta-analysis [CXCR4; 13 studies ( $n$ $=1936$ patients) and CXCL12; 38 studies $(n=5807$ patients)]. High expression of CXCL12 is associated with reduced overall survival in GC patients (HR 2.08; 95\% CI $=1.31-3.33 ; P=0.0002)^{[73]}$. CXCR4 expression is associated with shorter overall survival (HR 2.63; 95\% CI $=1.69-4.09 ; P<0.001)^{[74]}$.

Many studies have demonstrated that CXCR4 is the major chemokine receptor expressed in diverse cancer cells $^{[75]}$. Previous studies had shown that the CXCL12/CXCR4 axis plays an important role in invasion and metastasis. CXCL12, which is a ligand for CXCR4, activates the CXCR4 and attracts circulating CXCR4expression cells to peripheral tissues by regulating a wide variety of downstream signal pathways related to proliferation, migration, chemotaxis and cell survival ${ }^{[76]}$. CXCR4 levels in GC are also significantly higher than those in the normal mucous membrane. CXCR4 expression is significantly related to poor differentiation, high tumor stage and lymph node metastasis ${ }^{[77,78]}$. CXCR4 activates actin polymerization to induce cell motility and the EMT after binding its ligand CXCL12 ${ }^{[79]}$. CXCL12 rapidly and strongly phosphorylates Akt. Mammalian target of rapamycin (mTOR) pathways, which are located downstream of Akt, activate p70S6K (S6K) and eukaryotic initiation factor 4E binding protein 1 (4E-BP1). CXCL12/CXCR4 
activation also mediates integrin $\beta 1$ clustering at the cell surface and promotes the invasive ability of GC cells $^{[80]}$. In addition, CXCL12/CXCR4 upregulates the expression of MMP-2 and MMP-7 to assist EMT ${ }^{[81]}$. Runt-related transcription factor 2 (RUNX2) directly binds to the promoter region of the gene coding area for the chemokine receptor CXCR4 to enhance its transcription, as well as that of CXCL12. RUNX2 is a regulator of embryogenesis and development, and promotes the invasion and metastasis of GC by transcriptionally upregulating the chemokine receptor CXCR $4^{[82]}$.

CXCR7 is expressed in embryonic neuronal and heart tissue, some hematopoietic cells, and the activated endothelium $^{[83]}$. It is a receptor specific to SDF-1, and SDF-1 expression is strongly chemotactic for lymphocytes. It is also associated with lymph nodes in GC patients ${ }^{[84]}$. CXCR7 expression is upregulated in GC tissues. Overexpression of CXCR7 promotes cell proliferation, migration and invasion ${ }^{[85]}$ and it is associated with peritoneal dissemination and poor prognosis ${ }^{[86]}$.

Other chemokine receptors are also associated with GC progression and survival. CXCR1 is a class-A, rhodopsin-like G-protein-coupled receptor, which takes charge of cellular signal transduction and is targeted as a drug receptor ${ }^{[87]}$. CXCR1 functions as a high-affinity receptor for IL-8, which is a major mediator of inflammatory responses and tumorigenesis ${ }^{[88]}$. High expression of CXCR1 is associated with poorer overall survival in stage II and III GC patients. Importantly, stage II GC patients with higher CXCR1 expression have been shown to significantly benefit from 5 -fluorouracil (5-FU) based adjuvant chemotherapy ${ }^{[89,90]}$. CXCR2 expression strongly correlates with CXCR4 expression. CXCR2 expression changes according to the activity of CXCR4 signaling. CXCR4 and CXCR2 cross-activate each other to promote the metastasis of GC ${ }^{[91]}$. The co-expression of CXCR2 and IL-22 receptor 2 is associated with poor prognosis in GC. CXCR2 is involved in complex mechanisms and roles, and indicates a poor outcome in $\mathrm{GC}^{[92]}$.

Analysis of the expression levels of CXCR4 and CXCR7 revealed that these chemokine receptors are associated with the activation of the oncogenic pathway in GC. CXCL12, which is the ligand of CXCR4 and CXCR7 chemokines, is associated with poor prognosis in GC patients.

\section{MATRIX METALLOPROTEINASES}

MMPs are a family of endogenous calcium- and zinc-dependent proteolytic enzymes. Cancer cells in a microenvironment escape from the primary lesion through the surrounding ECM and intravasate into the lumina of blood vessels during metastatic progression. MMPs probably contribute to metastasis by secretion of pro-angiogenic and ECM-remodeling factors ${ }^{[93]}$. MMPs are capable of degrading ECM proteins and drive the loss of the basement membrane. The activation of MMPs and urokinase-type plasminogen activator (uPA) are required for expression of transcription factor Snail-1, which finally inhibits E-cadherin ${ }^{[94]}$. MMPs degrade most ECM components, and regulate other enzymes, chemokines and even cell receptors. Twenty-three types of MMPs have been described so $\mathrm{far}^{[95]}$. MMP-7, named matrilysin, is a distinct family member with proteolytic activity against a wide range of biomolecules including proteoglycans, laminin, fibronectin, casein and, more importantly, basement membrane collagen type IV. It is recognized as pivotal in the MMP family because it activates other MMPs (e.g. MMP-2 and MMP-9) for ECM degradation ${ }^{[96]}$ and possesses the highest activity in the MMP family ${ }^{[97]}$. MMP-7 regulates the activity of other biomolecules and MMP-7 degrades ECM protein. MMP-7 may play a central role in the stromal invasion of GC cells during the formation of peritoneal dissemination ${ }^{[98]}$. MMP-9 is known as type-IV collagenase or gelatinase $\mathrm{B}^{[99]}$.

Systematic reviews and meta-analyses have demonstrated the prognostic effects of MMP2, MMP7 and MMP9 in GC patients ${ }^{[100]}$. A meta-analysis of 10 studies (incorporating 1669 patients) was conducted to evaluate the relationship between MMP-2 and GC prognosis. Overexpression of MMP-2 is associated with TNM stage, depth of invasion, lymph node metastasis and distant metastasis. Overexpression of MMP-2 significantly predicts poor overall survival of GC patients $(\mathrm{HR}=1.92,95 \% \mathrm{CI}=1.48-2.48 ; P<0.001)^{[101]}$. 
A meta-analysis of nine studies (incorporating 1208 patients) was conducted to evaluate the relationship between MMP-7 and GC prognosis. Higher MMP-7 expression is associated with deeper invasion [pooled odds ratio $(\mathrm{OR})=3.20 ; 95 \% \mathrm{CI}=1.14-8.96 ; P=0.026$, higher $\mathrm{TNM}$ stage $($ pooled $\mathrm{OR}=3.67 ; 95 \% \mathrm{CI}=$ 2.281-5.99; $P<0.001$ ), lymph node metastasis (pooled $\mathrm{OR}=2.84 ; 95 \% \mathrm{CI}=1.89-4.25 ; P<0.001$ ), and distant metastasis (pooled $\mathrm{OR}=3.68 ; 95 \% \mathrm{CI}=1.85-7.29 ; P<0.001$ ), but not with histological grade. Higher MMP7 expression is associated with significantly shorter overall survival $(\mathrm{HR}=2.01,95 \% \mathrm{CI}=1.62-2.50, P<$ $0.001)^{[102]}$. Ten studies with 1478 patients were included to perform a meta-analysis of the survival results to evaluate the relationship between MMP-9 and GC prognosis. Overexpression of MMP-9 tends to be associated with lymph node metastasis $(\mathrm{OR}=1.91,95 \% \mathrm{CI}=1.40-2.59 ; P<0.05)$ and presence of vascular invasion $(\mathrm{OR}=2.64,95 \% \mathrm{CI}=1.52-4.59 ; P<0.05)$. MMP-9 overexpression is associated with shorter overall survival of $\mathrm{GC}$ patients $(\mathrm{HR}=1.69,95 \% \mathrm{Cl}=1.29-2.23 ; P<0.001)^{[103]}$.

Many factors that stimulate MMP expression have been reported in diverse cancer cells, such as interleukins ${ }^{[104-106]}$, epidermal growth factor ${ }^{[107]}$, fibroblast growth factor ${ }^{[108,109]}$ and NF-kB ${ }^{[110]}$. IL-1alpha induces MMP-1 in the stimulation of dermal fibroblasts of human melanoma cells ${ }^{[104]}$. MMP-9 and MMP-14 mRNA levels are selectively increased in response to EGFR activity in ovarian tumor cells ${ }^{[107]}$. FGF and STAT3 (Ser-727) are involved in the signaling leading to MMP-7 expression in prostate cancer ${ }^{[109]}$. In GC, IL-17A is involved in the pathology of inflammatory diseases and the tumor microenvironment. It could promote the invasion of GC cells by activating the NF-kB pathway, and subsequently upregulating the expression of MMP-2 and MMP-9 ${ }^{[106]}$. IL-10-stimulated macrophages also induce MMP-2 and MMP-9 activities in gastric and colorectal cancer cell lines ${ }^{[105]}$. Overexpression of HER2 is also associated with MMPs. HER2 overexpression is not only closely associated with tumor growth but is also related to tumor invasion. HER2 knockdown results in the downregulation of the expression of MMP- $9^{[111]}$.

\section{EXOSOMES IN THE TUMOR MICROENVIRONMENT}

Previous studies demonstrated that CAFs and cancer cells communicate by secreting a variety of cytokines, chemokines and $\mathrm{ECM}^{[112]}$. The mechanism underlying the communication among CAFs, NFs and cancer cells has been investigated. Recent extracellular vesicle assessments have demonstrated that cancer cells interact with the neighboring cells via soluble factors secreted into the extracellular space ${ }^{[113]}$. Extracellular vesicles can be classified into three main types according to size and biogenesis: exosomes (30-100 nm), microvesicles $(100-1000 \mathrm{~nm})$, and oncosomes $(1-10 \mu \mathrm{m})^{[114]}$. These three extracellular vesicle types play roles in cancer biology through vesicular transport.

Recent studies have demonstrated that exosomes are associated with GC progression and metastasis. GC cell-derived exosomes induce injury of peritoneal mesothelial cells through apoptosis and mesothelial-tomesenchymal transition, resulting in mesothelial barrier destruction and peritoneal fibrosis. GC-derived exosomes can facilitate peritoneal dissemination and a novel mechanism for GC peritoneal metastasis has been identified ${ }^{[115]}$. Next-generation sequencing technology provides more complete data and allows even deeper analyses of RNA transcriptomes. Exosomes from different GC cell lines and an immortalized normal gastric mucosal epithelial cell line were extracted and the amounts of exosomal proteins and RNAs were evaluated. According to the miRNA profiles of exosomes, miRNA-21-5p and miRNA-30a-5p were two of the most abundant sequences ${ }^{[116]}$. In another study, exosomal miRNA profiles in peritoneal fluid of peritoneal dissemination in GC were investigated. miRNA-21 was also identified as having the highest signal intensity and another five miRNAs (miRNA-1225-5p, miRNA-320c, miRNA-1202, miRNA-1207-5p and miRNA-4270) were identified ${ }^{[117]}$.

EGFR in exosomes secreted from GC cells can be delivered into the liver. The translocated EGFR on the plasma membrane of liver stromal cells activates HGF. The upregulated paracrine HGF, which binds the c-MET receptor on the migrated cancer cells, promotes liver metastases to favor the development of a 
Table 1. The association between the tumor microenvironments and survival of GC patients

\begin{tabular}{|c|c|c|c|c|c|c|}
\hline Factors & Marker & HR & $95 \% \mathrm{Cl}$ & $P$ value & Year & Journal \\
\hline \multicolumn{7}{|l|}{ CAFs } \\
\hline & IL1A, IL1B and TNF & 1.41 & $1.11-1.78$ & 0.004 & 2017 & Gastroenterology $^{[63]}$ \\
\hline \multicolumn{7}{|l|}{ BMDCs } \\
\hline & CD271 & 1.82 & $1.08-3.07$ & 0.025 & 2015 & BrJ Cancer $r^{[20]}$ \\
\hline \multicolumn{7}{|l|}{ TILs } \\
\hline & CD3+ TILs (intra-tumoral) & 0.52 & $0.43-0.63$ & $<0.001$ & 2017 & Oncotarget $t^{[28]}$ \\
\hline & FOXP3+ TILs (intra-tumoral) & 1.57 & $1.04-2.37$ & 0.033 & & \\
\hline & FOXP3+ TILs (extra-tumoral) & 0.76 & $0.60-0.96$ & 0.022 & & \\
\hline \multicolumn{7}{|l|}{ TAMs } \\
\hline & Total TAM & 1.71 & $1.19-2.45$ & 0.004 & 2016 & Genet Mol Res ${ }^{[4]]}$ \\
\hline & M1 macrophage & 0.46 & $0.33-0.65$ & $<0.001$ & & \\
\hline & M2 macrophage & 1.71 & $1.39-2.09$ & $<0.001$ & & \\
\hline \multicolumn{7}{|c|}{ Chemokines } \\
\hline & CXCR4 & 2.63 & $1.69-4.09$ & $<0.001$ & 2014 & Tumour Biol ${ }^{[74]}$ \\
\hline & CXCL12 & 2.08 & $1.31-3.33$ & 0.002 & 2017 & BrJ Cancer ${ }^{[73]}$ \\
\hline \multicolumn{7}{|l|}{ MMPs } \\
\hline & MMP-2 & 1.92 & $1.48-2.48$ & $<0.001$ & 2014 & Cancer Biother Radiopharm ${ }^{[101]}$ \\
\hline & MMP-7 & 2.01 & $1.62-2.50$ & $<0.001$ & 2015 & PLoS One ${ }^{[102]}$ \\
\hline & MMP-9 & 1.69 & $1.29-2.23$ & $<0.001$ & 2014 & Hepatogastroenterology ${ }^{[103]}$ \\
\hline
\end{tabular}

GC: gastric cancer; HR: hazard ratio; Cl: confidence interval; CAF: cancer associated fibroblast; IL: interleukin; TNF: tumor necrosis factor; BMDC: bone marrow-derived cell; TIL: tumor-infiltrating lymphocyte; TAM: tumor-associated macrophage; MMP: matrix metalloproteinase

liver-like microenvironment ${ }^{[118]}$. GC cell-derived exosomes stimulate the activation of the NF-kB pathway in macrophages, which promotes cancer progression in the tumor microenvironment ${ }^{[119]}$. The expression of miRNAs in exosomes of the peripheral blood has been investigated. High expression of miRNA-221 is associated with poor clinical prognosis in GC patients. Exosomes originating from BMDCs, which were transfected with miRNA-221 mimics, promote proliferation, invasion, migration and adhesion to the matrix of GC cell lines ${ }^{[120]}$. CD97 knockdown reduces the metastatic capacity of GC cells. Exosomes or conditioned medium from the SGC-L cells (GC cell line) activate proliferation and invasion as compared with that from SGC-L/CD97-knockdown cells. Exosomal CD97 is associated with CD55, CD44v6, $\alpha 5 \beta 1$ and CD31, and the exosome-dependent CD97 plays a role in premetastatic niche formation ${ }^{[121]}$.

Investigating exosomal miRNA secretion provides novel insight into communication among microenvironments of cancer cells. Dysregulation of miRNAs in CAFs, NFs and cancer cells can affect the secretory phenotype of cancer cells.

\section{CONCLUSIONS AND PERSPECTIVE}

This review describes the importance of the microenvironment of GC for cancer progression and metastasis. Major components of the microenvironments of GC consist of BMDCs, TILs, TAMs and CAFs. GC cells are also affected by these components, with chemokines and miRNA in extracellular vesicles such as the exosome. The accumulation of BMDCs is associated with Helicobacter pylori infection. Cytokines and growth factors secreted by BMDCs lead to cancer progression and metastasis. The amount of CD3+ TILs in the intra-tumoral compartment is the most significant prognostic marker. PD-L1 expression was significantly associated with the prognosis of GC patients owing to the interaction between PD-L1 and TILs. Increased levels of total TAM and M2 macrophage infiltration in GC patients are associated with worse overall survival. In contrast, elevated M1 macrophage density is associated with better overall survival. M2 macrophages might activate PD-L1 expression in tumor cells. Interleukins and miRNAs produced by CAFs are associated with cancer progression and metastasis of GC cells. CXCR4 and CXCL12 are associated with prognosis of GC patients. CXCL12 strongly activates the Akt pathway and upregulates the expression of MMP-2 and MMP-7 to assist EMT. These MMPs are capable of degrading ECM proteins and trigger the loss of the basement membrane. 
The microenvironments of GC are associated with lymphatic invasion, vascular invasion, lymph node metastasis and survival of GC patients [Table 1]. The interaction between GC cells and the microenvironments of GC is increasingly being recognized, and the microenvironments of GC, as well as GC cells, may have become a target of anticancer strategies. Future studies may investigate whether inhibitors of the interaction between GC cells and the microenvironments improve GC patient prognosis in preclinical studies. Much research in the field of microenvironments of GC and the accumulation of molecular biological investigation are important for improving the management of GC and overcoming this disease in the future.

\section{DECLARATIONS}

\section{Authors' contributions}

Drafting of the manuscript: Sawayama $\mathrm{H}$

Critical revision of the manuscript for important intellectual content: Ishimoto T, Baba $\mathrm{H}$

Financial support and sponsorship

None.

\section{Conflicts of interest}

There are no conflicts of interest.

\section{Patient consent}

Not applicable.

\section{Ethics approval}

Not applicable.

\section{Copyright}

(c) The Author(s) 2018.

\section{REFERENCES}

1. Torre LA, Bray F, Siegel RL, Ferlay J, Lortet-Tieulent J, Jemal A. Global cancer statistics, 2012. CA Cancer J Clin 2015;65:87-108.

2. Sasako M, Sano T, Yamamoto S, Kurokawa Y, Nashimoto A, Kurita A, Hiratsuka M, Tsujinaka T, Kinoshita T, Arai K, Yamamura Y, Okajima K. D2 lymphadenectomy alone or with para-aortic nodal dissection for gastric cancer. N Engl J Med 2008;359:453-62.

3. Waddell T, Verheij M, Allum W, Cunningham D, Cervantes A, Arnold D. Gastric cancer: ESMO-ESSO-ESTRO Clinical Practice Guidelines for diagnosis, treatment and follow-up. Ann Oncol 2013;24 Suppl 6:vi57-63.

4. Ajani JA, Bentrem DJ, Besh S, D’Amico TA, Das P, Denlinger C, Fakih MG, Fuchs CS, Gerdes H, Glasgow RE, Hayman JA, Hofstetter WL, Ilson DH, Keswani RN, Kleinberg LR, Korn WM, Lockhart AC, Meredith K, Mulcahy MF, Orringer MB, Posey JA, Sasson AR, Scott WJ, Strong VE, Varghese TK, Jr., Warren G, Washington MK, Willett C, Wright CD, McMillian NR, Sundar H. Gastric cancer, version 2.2013: featured updates to the NCCN Guidelines. J Natl Compr Canc Netw 2013;11:531-46.

5. Wilke H, Muro K, Van Cutsem E, Oh SC, Bodoky G, Shimada Y, Hironaka S, Sugimoto N, Lipatov O, Kim TY, Cunningham D, Rougier P, Komatsu Y, Ajani J, Emig M, Carlesi R, Ferry D, Chandrawansa K, Schwartz JD, Ohtsu A. Ramucirumab plus paclitaxel versus placebo plus paclitaxel in patients with previously treated advanced gastric or gastro-oesophageal junction adenocarcinoma (RAINBOW): a double-blind, randomised phase 3 trial. Lancet Oncol 2014;15:1224-35.

6. Fuchs CS, Tomasek J, Yong CJ, Dumitru F, Passalacqua R, Goswami C, Safran H, Dos Santos LV, Aprile G, Ferry DR, Melichar B, Tehfe M, Topuzov E, Zalcberg JR, Chau I, Campbell W, Sivanandan C, Pikiel J, Koshiji M, Hsu Y, Liepa AM, Gao L, Schwartz JD, Tabernero J. Ramucirumab monotherapy for previously treated advanced gastric or gastro-oesophageal junction adenocarcinoma (REGARD): an international, randomised, multicentre, placebo-controlled, phase 3 trial. Lancet 2014;383:31-9.

7. Bang YJ, Van Cutsem E, Feyereislova A, Chung HC, Shen L, Sawaki A, Lordick F, Ohtsu A, Omuro Y, Satoh T, Aprile G, Kulikov E, Hill J, Lehle M, Ruschoff J, Kang YK. Trastuzumab in combination with chemotherapy versus chemotherapy alone for treatment of HER2positive advanced gastric or gastro-oesophageal junction cancer (ToGA): a phase 3, open-label, randomised controlled trial. Lancet 2010;376:687-97.

8. Kang YK, Boku N, Satoh T, Ryu MH, Chao Y, Kato K, Chung HC, Chen JS, Muro K, Kang WK, Yeh KH, Yoshikawa T, Oh SC, Bai LY, Tamura T, Lee KW, Hamamoto Y, Kim JG, Chin K, Oh DY, Minashi K, Cho JY, Tsuda M, Chen LT. Nivolumab in patients with advanced gastric or gastro-oesophageal junction cancer refractory to, or intolerant of, at least two previous chemotherapy regimens (ONO-4538-12, 
ATTRACTION-2): a randomised, double-blind, placebo-controlled, phase 3 trial. Lancet 2017;390:2461-71.

9. Cancer Genome Atlas Research Network. Comprehensive molecular characterization of gastric adenocarcinoma. Nature 2014;513:202-9.

10. Houghton J, Stoicov C, Nomura S, Rogers AB, Carlson J, Li H, Cai X, Fox JG, Goldenring JR, Wang TC. Gastric cancer originating from bone marrow-derived cells. Science 2004;306:1568-71.

11. Quante M, Tu SP, Tomita H, Gonda T, Wang SS, Takashi S, Baik GH, Shibata W, Diprete B, Betz KS, Friedman R, Varro A, Tycko B, Wang TC. Bone marrow-derived myofibroblasts contribute to the mesenchymal stem cell niche and promote tumor growth. Cancer Cell 2011;19:257-72.

12. Varon C, Dubus P, Mazurier F, Asencio C, Chambonnier L, Ferrand J, Giese A, Senant-Dugot N, Carlotti M, Megraud F. Helicobacter pylori infection recruits bone marrow-derived cells that participate in gastric preneoplasia in mice. Gastroenterology 2012;142:281-91.

13. Ferrand J, Lehours P, Schmid-Alliana A, Megraud F, Varon C. Helicobacter pylori infection of gastrointestinal epithelial cells in vitro induces mesenchymal stem cell migration through an NF-kappaB-dependent pathway. PLoS One 2011;6:e29007.

14. Zhu L, Cheng X, Shi J, Jiacheng L, Chen G, Jin H, Liu AB, Pyo H, Ye J, Zhu Y, Wang H, Chen H, Fang J, Cai L, Wang TC, Yang $\mathrm{CS}$, Tu SP. Crosstalk between bone marrow-derived myofibroblasts and gastric cancer cells regulates cancer stemness and promotes tumorigenesis. Oncogene 2016;35:5388-99.

15. Zhu M, Wang M, Yang F, Tian Y, Cai J, Yang H, Fu H, Mao F, Zhu W, Qian H, Xu W. miR-155-5p inhibition promotes the transition of bone marrow mesenchymal stem cells to gastric cancer tissue derived MSC-like cells via NF-kappaB p65 activation. Oncotarget 2016;7:16567-80.

16. Kasashima H, Yashiro M, Nakamae H, Kitayama K, Masuda G, Kinoshita H, Fukuoka T, Hasegawa T, Nakane T, Hino M, Hirakawa K, Ohira M. CXCL1-chemokine (C-X-C Motif) receptor 2 signaling stimulates the recruitment of bone marrow-derived mesenchymal cells into diffuse-type gastric cancer stroma. Am J Pathol 2016;186:3028-39.

17. Buhring HJ, Treml S, Cerabona F, de Zwart P, Kanz L, Sobiesiak M. Phenotypic characterization of distinct human bone marrow-derived MSC subsets. Ann N Y Acad Sci 2009;1176:124-34.

18. Boxall SA, Jones E. Markers for characterization of bone marrow multipotential stromal cells. Stem Cells Int 2012;2012:975871.

19. Jones EA, Crawford A, English A, Henshaw K, Mundy J, Corscadden D, Chapman T, Emery P, Hatton P, McGonagle D. Synovial fluid mesenchymal stem cells in health and early osteoarthritis: detection and functional evaluation at the single-cell level. Arthritis Rheum 2008:58:1731-40.

20. Kasashima H, Yashiro M, Nakamae H, Masuda G, Kinoshita H, Morisaki T, Fukuoka T, Hasegawa T, Sakurai K, Toyokawa T, Kubo N, Tanaka H, Muguruma K, Ohira M, Nakane T, Hino M, Hirakawa K. Bone marrow-derived stromal cells are associated with gastric cancer progression. Br J Cancer 2015;113:443-52.

21. Khazaie K, Blatner NR, Khan MW, Gounari F, Gounaris E, Dennis K, Bonertz A, Tsai FN, Strouch MJ, Cheon E, Phillips JD, Beckhove P, Bentrem DJ. The significant role of mast cells in cancer. Cancer Metastasis Rev 2011;30:45-60.

22. Mukherjee S, Bandyopadhyay G, Dutta C, Bhattacharya A, Karmakar R, Barui G. Evaluation of endoscopic biopsy in gastric lesions with a special reference to the significance of mast cell density. Indian J Pathol Microbiol 2009;52:20-4.

23. Zhao Y, Wu K, Cai K, Zhai R, Tao K, Wang G, Wang J. Increased numbers of gastric-infiltrating mast cells and regulatory $\mathrm{T}$ cells are associated with tumor stage in gastric adenocarcinoma patients. Oncol Lett 2012;4:755-8.

24. Ribatti D, Guidolin D, Marzullo A, Nico B, Annese T, Benagiano V, Crivellato E. Mast cells and angiogenesis in gastric carcinoma. Int J Exp Pathol 2010;91:350-6.

25. Lin C, Liu H, Zhang H, Cao Y, Li R, Wu S, Li H, He H, Xu J, Sun Y. Tryptase expression as a prognostic marker in patients with resected gastric cancer. Br J Surg 2017;104:1037-44.

26. Shikotra A, Ohri CM, Green RH, Waller DA, Bradding P. Mast cell phenotype, TNFalpha expression and degranulation status in nonsmall cell lung cancer. Sci Rep 2016;6:38352.

27. Balkwill F, Mantovani A. Inflammation and cancer: back to Virchow? Lancet 2001;357:539-45.

28. Zheng X, Song X, Shao Y, Xu B, Chen L, Zhou Q, Hu W, Zhang D, Wu C, Tao M, Zhu Y, Jiang J. Prognostic role of tumor-infiltrating lymphocytes in gastric cancer: a meta-analysis. Oncotarget 2017;8:57386-98.

29. Kang BW, Seo AN, Yoon S, Bae HI, Jeon SW, Kwon OK, Chung HY, Yu W, Kang H, Kim JG. Prognostic value of tumor-infiltrating lymphocytes in Epstein-Barr virus-associated gastric cancer. Ann Oncol 2016;27:494-501.

30. Kim KJ, Lee KS, Cho HJ, Kim YH, Yang HK, Kim WH, Kang GH. Prognostic implications of tumor-infiltrating FoxP3+ regulatory T cells and CD8+ cytotoxic T cells in microsatellite-unstable gastric cancers. Hum Pathol 2014;45:285-93.

31. Ma J, Li J, Hao Y, Nie Y, Li Z, Qian M, Liang Q, Yu J, Zeng M, Wu K. Differentiated tumor immune microenvironment of Epstein-Barr virus-associated and negative gastric cancer: implication in prognosis and immunotherapy. Oncotarget 2017;8:67094-103.

32. Kawazoe A, Kuwata T, Kuboki Y, Shitara K, Nagatsuma AK, Aizawa M, Yoshino T, Doi T, Ohtsu A, Ochiai A. Clinicopathological features of programmed death ligand 1 expression with tumor-infiltrating lymphocyte, mismatch repair, and Epstein-Barr virus status in a large cohort of gastric cancer patients. Gastric Cancer 2017;20:407-15.

33. Fang W, Chen Y, Sheng J, Zhou T, Zhang Y, Zhan J, Liu L, Huang J, Peng P, Zhang L. Association between PD-L1 expression on tumourinfiltrating lymphocytes and overall survival in patients with gastric cancer. $J$ Cancer 2017;8:1579-85.

34. Kim KJ, Yang HK, Kim WH, Kang GH. Combined prognostic effect of PD-L1 expression and immunoscore in microsatellite-unstable advanced gastric cancers. Oncotarget 2017;8:58887-902.

35. Kim JW, Nam KH, Ahn SH, Park DJ, Kim HH, Kim SH, Chang H, Lee JO, Kim YJ, Lee HS, Kim JH, Bang SM, Lee JS, Lee KW. Prognostic implications of immunosuppressive protein expression in tumors as well as immune cell infiltration within the tumor microenvironment in gastric cancer. Gastric Cancer 2016;19:42-52.

36. Koh J, Ock CY, Kim JW, Nam SK, Kwak Y, Yun S, Ahn SH, Park DJ, Kim HH, Kim WH, Lee HS. Clinicopathologic implications of immune classification by PD-L1 expression and CD8-positive tumor-infiltrating lymphocytes in stage II and III gastric cancer patients. Oncotarget 2017;8:26356-67. 
37. Zheng X, Turkowski K, Mora J, Brune B, Seeger W, Weigert A, Savai R. Redirecting tumor-associated macrophages to become tumoricidal effectors as a novel strategy for cancer therapy. Oncotarget 2017;8:48436-52.

38. Franklin RA, Liao W, Sarkar A, Kim MV, Bivona MR, Liu K, Pamer EG, Li MO. The cellular and molecular origin of tumor-associated macrophages. Science 2014;344:921-5.

39. O’Sullivan T, Saddawi-Konefka R, Vermi W, Koebel CM, Arthur C, White JM, Uppaluri R, Andrews DM, Ngiow SF, Teng MW, Smyth MJ, Schreiber RD, Bui JD. Cancer immunoediting by the innate immune system in the absence of adaptive immunity. $J$ Exp Med 2012;209:1869-82.

40. Luo Y, Zhou H, Krueger J, Kaplan C, Lee SH, Dolman C, Markowitz D, Wu W, Liu C, Reisfeld RA, Xiang R. Targeting tumor-associated macrophages as a novel strategy against breast cancer. $J$ Clin Invest 2006;116:2132-41.

41. Wang XL, Jiang JT, Wu CP. Prognostic significance of tumor-associated macrophage infiltration in gastric cancer: a meta-analysis. Genet Mol Res 2016;15:gmr15049040.

42. Tauchi Y, Tanaka H, Kumamoto K, Tokumoto M, Sakimura C, Sakurai K, Kimura K, Toyokawa T, Amano R, Kubo N, Muguruma K, Yashiro M, Maeda K, Ohira M, Hirakawa K. Tumor-associated macrophages induce capillary morphogenesis of lymphatic endothelial cells derived from human gastric cancer. Cancer Sci 2016;107:1101-9.

43. Kim KJ, Wen XY, Yang HK, Kim WH, Kang GH. Prognostic implication of M2 macrophages are determined by the proportional balance of tumor associated macrophages and tumor infiltrating lymphocytes in microsatellite-unstable gastric carcinoma. PLoS One 2015;10:e144192.

44. Ishimoto T, Sugihara H, Watanabe M, Sawayama H, Iwatsuki M, Baba Y, Okabe H, Hidaka K, Yokoyama N, Miyake K, Yoshikawa M, Nagano O, Komohara Y, Takeya M, Saya H, Baba H. Macrophage-derived reactive oxygen species suppress miR-328 targeting CD44 in cancer cells and promote redox adaptation. Carcinogenesis 2014;35:1003-11.

45. Aruffo A, Stamenkovic I, Melnick M, Underhill CB, Seed B. CD44 is the principal cell surface receptor for hyaluronate. Cell 1990;61:1303-13.

46. Screaton GR, Caceres JF, Mayeda A, Bell MV, Plebanski M, Jackson DG, Bell JI, Krainer AR. Identification and characterization of three members of the human SR family of pre-mRNA splicing factors. EMBO J 1995;14:4336-49.

47. Screaton GR, Bell MV, Jackson DG, Cornelis FB, Gerth U, Bell JI. Genomic structure of DNA encoding the lymphocyte homing receptor CD44 reveals at least 12 alternatively spliced exons. Proc Natl Acad Sci U S A 1992;89:12160-4.

48. Takaishi S, Okumura T, Tu S, Wang SS, Shibata W, Vigneshwaran R, Gordon SA, Shimada Y, Wang TC. Identification of gastric cancer stem cells using the cell surface marker CD44. Stem Cells 2009;27:1006-20.

49. Ishimoto T, Nagano O, Yae T, Tamada M, Motohara T, Oshima H, Oshima M, Ikeda T, Asaba R, Yagi H, Masuko T, Shimizu T, Ishikawa T, Kai K, Takahashi E, Imamura Y, Baba Y, Ohmura M, Suematsu M, Baba H, Saya H. CD44 variant regulates redox status in cancer cells by stabilizing the xCT subunit of system xc(-) and thereby promotes tumor growth. Cancer Cell 2011;19:387-400.

50. Wyckoff JB, Wang Y, Lin EY, Li JF, Goswami S, Stanley ER, Segall JE, Pollard JW, Condeelis J. Direct visualization of macrophageassisted tumor cell intravasation in mammary tumors. Cancer Res 2007;67:2649-56.

51. Bonde AK, Tischler V, Kumar S, Soltermann A, Schwendener RA. Intratumoral macrophages contribute to epithelial-mesenchymal transition in solid tumors. BMC Cancer 2012;12:35.

52. Wu MH, Lee WJ, Hua KT, Kuo ML, Lin MT. Macrophage infiltration induces gastric cancer invasiveness by activating the beta-catenin pathway. PLoS One 2015;10:e134122.

53. Guo J, Yan Y, Guo Q, Zhang M, Zhang J, Goltzman D. Tumor-associated macrophages induce the expression of FOXQ1 to promote epithelial-mesenchymal transition and metastasis in gastric cancer cells. Oncol Rep 2017;38:2003-10.

54. Sugihara H, Ishimoto T, Watanabe M, Sawayama H, Iwatsuki M, Baba Y, Komohara Y, Takeya M, Baba H. Identification of miR-30e* regulation of Bmi1 expression mediated by tumor-associated macrophages in gastrointestinal cancer. PLoS One 2013;8:e81839.

55. Abiko K, Matsumura N, Hamanishi J, Horikawa N, Murakami R, Yamaguchi K, Yoshioka Y, Baba T, Konishi I, Mandai M. IFN-gamma from lymphocytes induces PD-L1 expression and promotes progression of ovarian cancer. Br J Cancer 2015;112:1501-9.

56. Soliman H, Khalil F, Antonia S. PD-L1 expression is increased in a subset of basal type breast cancer cells. PLoS One 2014;9:e88557.

57. Harada K, Dong X, Estrella JS, Correa AM, Xu Y, Hofstetter WL, Sudo K, Onodera H, Suzuki K, Suzuki A, Johnson RL, Wang Z, Song $\mathrm{S}$, Ajani JA. Tumor-associated macrophage infiltration is highly associated with PD-L1 expression in gastric adenocarcinoma. Gastric Cancer 2018;21:31-40.

58. Kalluri R, Zeisberg M. Fibroblasts in cancer. Nat Rev Cancer 2006;6:392-401.

59. Yamaguchi H, Sakai R. Direct interaction between carcinoma cells and cancer associated fibroblasts for the regulation of cancer invasion. Cancers (Basel) 2015;7:2054-62.

60. De Wever O, Demetter P, Mareel M, Bracke M. Stromal myofibroblasts are drivers of invasive cancer growth. Int J Cancer 2008;123:2229-38.

61. Bissell MJ, Hines WC. Why don't we get more cancer? A proposed role of the microenvironment in restraining cancer progression. Nat Med 2011;17:320-9.

62. Wen X, He X, Jiao F, Wang C, Sun Y, Ren X, Li Q. Fibroblast activation protein-alpha-positive fibroblasts promote gastric cancer progression and resistance to immune checkpoint blockade. Oncol Res 2017;25:629-40.

63. Ishimoto T, Miyake K, Nandi T, Yashiro M, Onishi N, Huang KK, Lin SJ, Kalpana R, Tay ST, Suzuki Y, Cho BC, Kuroda D, Arima K, Izumi D, Iwatsuki M, Baba Y, Oki E, Watanabe M, Saya H, Hirakawa K, Baba H, Tan P. Activation of transforming growth factor beta 1 signaling in gastric cancer-associated fibroblasts increases their motility, via expression of rhomboid 5 homolog 2, and ability to induce invasiveness of gastric cancer cells. Gastroenterology 2017;153:191-204.e16.

64. Wu X, Tao P, Zhou Q, Li J, Yu Z, Wang X, Li C, Yan M, Zhu Z, Liu B, Su L. IL-6 secreted by cancer-associated fibroblasts promotes epithelial-mesenchymal transition and metastasis of gastric cancer via JAK2/STAT3 signaling pathway. Oncotarget 2017;8:20741-50

65. Bie Q, Zhang B, Sun C, Ji X, Barnie PA, Qi C, Peng J, Zhang D, Zheng D, Su Z, Wang S, Xu H. IL-17B activated mesenchymal stem 
cells enhance proliferation and migration of gastric cancer cells. Oncotarget 2017;8:18914-23.

66. Yan Y, Wang LF, Wang RF. Role of cancer-associated fibroblasts in invasion and metastasis of gastric cancer. World J Gastroenterol 2015;21:9717-26.

67. Yang TS, Yang XH, Chen X, Wang XD, Hua J, Zhou DL, Zhou B, Song ZS. MicroRNA-106b in cancer-associated fibroblasts from gastric cancer promotes cell migration and invasion by targeting PTEN. FEBS Lett 2014;588:2162-9.

68. Naito Y, Sakamoto N, Oue N, Yashiro M, Sentani K, Yanagihara K, Hirakawa K, Yasui W. MicroRNA-143 regulates collagen type III expression in stromal fibroblasts of scirrhous type gastric cancer. Cancer Sci 2014;105:228-35.

69. Kurashige J, Mima K, Sawada G, Takahashi Y, Eguchi H, Sugimachi K, Mori M, Yanagihara K, Yashiro M, Hirakawa K, Baba H, Mimori K. Epigenetic modulation and repression of miR-200b by cancer-associated fibroblasts contribute to cancer invasion and peritoneal dissemination in gastric cancer. Carcinogenesis 2015;36:133-41.

70. Lee KW, Yeo SY, Sung CO, Kim SH. Twist1 is a key regulator of cancer-associated fibroblasts. Cancer Res 2015;75:73-85.

71. Sung CO, Lee KW, Han S, Kim SH. Twist1 is up-regulated in gastric cancer-associated fibroblasts with poor clinical outcomes. Am J Pathol 2011;179:1827-38.

72. Lippitz BE. Cytokine patterns in patients with cancer: a systematic review. Lancet Oncol 2013;14:e218-28.

73. Samarendra H, Jones K, Petrinic T, Silva MA, Reddy S, Soonawalla Z, Gordon-Weeks A. A meta-analysis of CXCL12 expression for cancer prognosis. Br J Cancer 2017;117:124-35.

74. Han M, Lv S, Zhang Y, Yi R, Huang B, Fu H, Bian R, Li X. The prognosis and clinicopathology of CXCR4 in gastric cancer patients: a meta-analysis. Tumour Biol 2014;35:4589-97.

75. Balkwill F. The significance of cancer cell expression of the chemokine receptor CXCR4. Semin Cancer Biol 2004;14:171-9.

76. Teicher BA, Fricker SP. CXCL12 (SDF-1)/CXCR4 pathway in cancer. Clin Cancer Res 2010;16:2927-31.

77. He H, Wang C, Shen Z, Fang Y, Wang X, Chen W, Liu F, Qin X, Sun Y. Upregulated expression of C-X-C chemokine receptor 4 is an independent prognostic predictor for patients with gastric cancer. PLoS One 2013;8:e71864.

78. Lee HJ, Kim SW, Kim HY, Li S, Yun HJ, Song KS, Kim S, Jo DY. Chemokine receptor CXCR4 expression, function, and clinical implications in gastric cancer. Int J Oncol 2009;34:473-80.

79. Chen G, Chen SM, Wang X, Ding XF, Ding J, Meng LH. Inhibition of chemokine (CXC motif) ligand 12/chemokine (CXC motif) receptor 4 axis (CXCL12/CXCR4)-mediated cell migration by targeting mammalian target of rapamycin (mTOR) pathway in human gastric carcinoma cells. J Biol Chem 2012;287:12132-41.

80. Izumi D, Ishimoto T, Miyake K, Sugihara H, Eto K, Sawayama H, Yasuda T, Kiyozumi Y, Kaida T, Kurashige J, Imamura Y, Hiyoshi Y, Iwatsuki M, Iwagami S, Baba Y, Sakamoto Y, Miyamoto Y, Yoshida N, Watanabe M, Takamori H, Araki N, Tan P, Baba H. CXCL12/ CXCR4 activation by cancer-associated fibroblasts promotes integrin betal clustering and invasiveness in gastric cancer. Int $J$ Cancer 2016;138:1207-19.

81. Hashimoto I, Koizumi K, Tatematsu M, Minami T, Cho S, Takeno N, Nakashima A, Sakurai H, Saito S, Tsukada K, Saiki I. Blocking on the CXCR4/mTOR signalling pathway induces the anti-metastatic properties and autophagic cell death in peritoneal disseminated gastric cancer cells. Eur J Cancer 2008;44:1022-9.

82. Guo ZJ, Yang L, Qian F, Wang YX, Yu X, Ji CD, Cui W, Xiang DF, Zhang X, Zhang P, Wang JM, Cui YH, Bian XW. Transcription factor RUNX2 up-regulates chemokine receptor CXCR4 to promote invasive and metastatic potentials of human gastric cancer. Oncotarget 2016;7:20999-1012.

83. Tiveron MC, Boutin C, Daou P, Moepps B, Cremer H. Expression and function of CXCR7 in the mouse forebrain. J Neuroimmunol 2010;224:72-9.

84. Cheng Y, Qu J, Che X, Xu L, Song N, Ma Y, Gong J, Qu X, Liu Y. CXCL12/SDF-1alpha induces migration via SRC-mediated CXCR4EGFR cross-talk in gastric cancer cells. Oncol Lett 2017;14:2103-10.

85. Xin Q, Zhang N, Yu HB, Zhang Q, Cui YF, Zhang CS, Ma Z, Yang Y, Liu W. CXCR7/CXCL12 axis is involved in lymph node and liver metastasis of gastric carcinoma. World J Gastroenterol 2017;23:3053-65.

86. Nambara S, Iguchi T, Oki E, Tan P, Maehara Y, Mimori K. Overexpression of CXCR7 is a novel prognostic indicator in gastric cancer. Dig Surg 2017;34:312-8.

87. Park SH, Das BB, Casagrande F, Tian Y, Nothnagel HJ, Chu M, Kiefer H, Maier K, De Angelis AA, Marassi FM, Opella SJ. Structure of the chemokine receptor CXCR1 in phospholipid bilayers. Nature 2012;491:779-83.

88. Sallusto F, Baggiolini M. Chemokines and leukocyte traffic. Nat Immunol 2008;9:949-52.

89. Cao Y, Liu H, Zhang H, Lin C, Li R, Wu S, Li H, He H, Zhang W, Xu J. CXC chemokine receptor 1 predicts postoperative prognosis and chemotherapeutic benefits for TNM II and III resectable gastric cancer patients. Oncotarget 2017;8:20328-39.

90. Wang J, Hu W, Wang K, Yu J, Luo B, Luo G, Wang W, Wang H, Li J, Wen J. Repertaxin, an inhibitor of the chemokine receptors CXCR1 and CXCR2, inhibits malignant behavior of human gastric cancer MKN45 cells in vitro and in vivo and enhances efficacy of 5-fluorouracil. Int J Oncol 2016;48:1341-52.

91. Xiang Z, Zhou ZJ, Xia GK, Zhang XH, Wei ZW, Zhu JT, Yu J, Chen W, He Y, Schwarz RE, Brekken RA, Awasthi N, Zhang CH. A positive crosstalk between CXCR4 and CXCR2 promotes gastric cancer metastasis. Oncogene 2017;36:5122-33.

92. Yang SB, Han F, Wu JH, Zhao Z, Zhan W. Association between CXCR2 and IL-22BP expression indicate a poor outcome for gastric adenocarcinoma progression. Oncol Lett 2016;12:1477-84.

93. Peinado H, Lavotshkin S, Lyden D. The secreted factors responsible for pre-metastatic niche formation: old sayings and new thoughts. Semin Cancer Biol 2011;21:139-46.

94. Kanda M, Kodera Y. Molecular mechanisms of peritoneal dissemination in gastric cancer. World J Gastroenterol 2016;22:6829-40.

95. Brinckerhoff CE, Matrisian LM. Matrix metalloproteinases: a tail of a frog that became a prince. Nat Rev Mol Cell Biol 2002;3:207-14.

96. Parsons SL, Watson SA, Brown PD, Collins HM, Steele RJ. Matrix metalloproteinases. Br J Surg 1997;84:160-6.

97. Imai K, Yokohama Y, Nakanishi I, Ohuchi E, Fujii Y, Nakai N, Okada Y. Matrix metalloproteinase 7 (matrilysin) from human rectal 
carcinoma cells. Activation of the precursor, interaction with other matrix metalloproteinases and enzymic properties. $J$ Biol Chem 1995;270:6691-7.

98. Ii M, Yamamoto H, Adachi Y, Maruyama Y, Shinomura Y. Role of matrix metalloproteinase-7 (matrilysin) in human cancer invasion, apoptosis, growth, and angiogenesis. Exp Biol Med (Maywood) 2006;231:20-7.

99. Nagase H, Woessner JF Jr. Matrix metalloproteinases. J Biol Chem 1999;274:21491-4.

100. Shen W, Xi H, Wei B, Chen L. The prognostic role of matrix metalloproteinase 2 in gastric cancer: a systematic review with metaanalysis. J Cancer Res Clin Oncol 2014;140:1003-9.

101. Wang HL, Zhou PY, Zhang Y, Liu P. Relationships between abnormal MMP2 expression and prognosis in gastric cancer: a meta-analysis of cohort studies. Cancer Biother Radiopharm 2014;29:166-72.

102. Soleyman-Jahi S, Nedjat S, Abdirad A, Hoorshad N, Heidari R, Zendehdel K. Prognostic significance of matrix metalloproteinase-7 in gastric cancer survival: a meta-analysis. PLoS One 2014;10:e0122316.

103. Chen J, Chen LJ, Zhou HC, Yang RB, Lu Y, Xia YL, Wu W, Hu LW. Prognostic value of matrix metalloproteinase-9 in gastric cancer: a meta-analysis. Hepatogastroenterology 2014;61:518-24.

104. Loffek S, Zigrino P, Angel P, Anwald B, Krieg T, Mauch C. High invasive melanoma cells induce matrix metalloproteinase-1 synthesis in fibroblasts by interleukin-1alpha and basic fibroblast growth factor-mediated mechanisms. J Invest Dermatol 2005;124:638-43.

105. Cardoso AP, Pinto ML, Pinto AT, Pinto MT, Monteiro C, Oliveira MI, Santos SG, Relvas JB, Seruca R, Mantovani A, Mareel M, Barbosa MA, Oliveira MJ. Matrix metalloproteases as maestros for the dual role of LPS- and IL-10-stimulated macrophages in cancer cell behaviour. BMC Cancer 2015;15:456.

106. Wang Y, Wu H, Wu X, Bian Z, Gao Q. Interleukin 17A promotes gastric cancer invasiveness via NF-kappaB mediated matrix metalloproteinases 2 and 9 expression. PLoS One 2014;9:e96678.

107. Cowden Dahl KD, Zeineldin R, Hudson LG. PEA3 is necessary for optimal epidermal growth factor receptor-stimulated matrix metalloproteinase expression and invasion of ovarian tumor cells. Mol Cancer Res 2007;5:413-21.

108. Toschi E, Barillari G, Sgadari C, Bacigalupo I, Cereseto A, Carlei D, Palladino C, Zietz C, Leone P, Sturzl M, Butto S, Cafaro A, Monini $\mathrm{P}$, Ensoli B. Activation of matrix-metalloproteinase-2 and membrane-type-1-matrix-metalloproteinase in endothelial cells and induction of vascular permeability in vivo by human immunodeficiency virus-1 Tat protein and basic fibroblast growth factor. Mol Biol Cell 2001;12:2934-46.

109. Udayakumar TS, Stratton MS, Nagle RB, Bowden GT. Fibroblast growth factor-1 induced promatrilysin expression through the activation of extracellular-regulated kinases and STAT3. Neoplasia 2002;4:60-7.

110. Bond M, Fabunmi RP, Baker AH, Newby AC. Synergistic upregulation of metalloproteinase- 9 by growth factors and inflammatory cytokines: an absolute requirement for transcription factor NF-kappa B. FEBS Lett 1998;435:29-34.

111. Shan YQ, Ying RC, Zhou CH, Zhu AK, Ye J, Zhu W, Ju TF, Jin HC. MMP-9 is increased in the pathogenesis of gastric cancer by the mediation of HER2. Cancer Gene Ther 2015;22:101-7.

112. Liu J, Chen S, Wang W, Ning BF, Chen F, Shen W, Ding J, Chen W, Xie WF, Zhang X. Cancer-associated fibroblasts promote hepatocellular carcinoma metastasis through chemokine-activated hedgehog and TGF-beta pathways. Cancer Lett 2016;379:49-59.

113. Shifrin DA Jr, Demory Beckler M, Coffey RJ, Tyska MJ. Extracellular vesicles: communication, coercion, and conditioning. Mol Biol Cell 2013;24:1253-9.

114. Raposo G, Stoorvogel W. Extracellular vesicles: exosomes, microvesicles, and friends. J Cell Biol 2013;200:373-83.

115. Deng G, Qu J, Zhang Y, Che X, Cheng Y, Fan Y, Zhang S, Na D, Liu Y, Qu X. Gastric cancer-derived exosomes promote peritoneal metastasis by destroying the mesothelial barrier. FEBS Lett 2017;591:2167-79.

116. Ren J, Zhou Q, Li H, Li J, Pang L, Su L, Gu Q, Zhu Z, Liu B. Characterization of exosomal RNAs derived from human gastric cancer cells by deep sequencing. Tumour Biol 2017;39:1010428317695012.

117. Tokuhisa M, Ichikawa Y, Kosaka N, Ochiya T, Yashiro M, Hirakawa K, Kosaka T, Makino H, Akiyama H, Kunisaki C, Endo I. Exosomal miRNAs from peritoneum lavage fluid as potential prognostic biomarkers of peritoneal metastasis in gastric cancer. PLoS One 2015;10:e130472.

118. Zhang H, Deng T, Liu R, Bai M, Zhou L, Wang X, Li S, Yang H, Li J, Ning T, Huang D, Li H, Zhang L, Ying G, Ba Y. Exosomedelivered EGFR regulates liver microenvironment to promote gastric cancer liver metastasis. Nat Commun 2017;8:15016.

119. Wu L, Zhang X, Zhang B, Shi H, Yuan X, Sun Y, Pan Z, Qian H, Xu W. Exosomes derived from gastric cancer cells activate NF-kappaB pathway in macrophages to promote cancer progression. Tumour Biol 2016;37:12169-80.

120. Ma M, Chen S, Liu Z, Xie H, Deng H, Shang S, Wang X, Xia M, Zuo C. miRNA-221 of exosomes originating from bone marrow mesenchymal stem cells promotes oncogenic activity in gastric cancer. Onco Targets Ther 2017;10:4161-71.

121. Liu D, Li C, Trojanowicz B, Li X, Shi D, Zhan C, Wang Z, Chen L. CD97 promotion of gastric carcinoma lymphatic metastasis is exosome dependent. Gastric Cancer 2016;19:754-66. 